\title{
Pathophysiology, diagnosis, and treatment of spinal meningoceles and arachnoid cysts
}

\author{
Ryan M. Dahlgren \\ University of Oklahoma \\ Eli M. Baron \\ Temple University \\ Alexander R. Vaccaro \\ Thomas Jefferson University
}

Follow this and additional works at: https://jdc.jefferson.edu/orthofp

Part of the Orthopedics Commons

Let us know how access to this document benefits you

\section{Recommended Citation}

Dahlgren, Ryan M.; Baron, Eli M.; and Vaccaro, Alexander R., "Pathophysiology, diagnosis, and treatment of spinal meningoceles and arachnoid cysts" (2007). Department of Orthopaedic Surgery Faculty Papers. Paper 4.

https://jdc.jefferson.edu/orthofp/4

This Article is brought to you for free and open access by the Jefferson Digital Commons. The Jefferson Digital Commons is a service of Thomas Jefferson University's Center for Teaching and Learning (CTL). The Commons is a showcase for Jefferson books and journals, peer-reviewed scholarly publications, unique historical collections from the University archives, and teaching tools. The Jefferson Digital Commons allows researchers and interested readers anywhere in the world to learn about and keep up to date with Jefferson scholarship. This article has been accepted for inclusion in Department of Orthopaedic Surgery Faculty Papers by an authorized administrator of the Jefferson Digital Commons. For more information, please contact: JeffersonDigitalCommons@jefferson.edu. 
Pathophysiology, Diagnosis, and Treatment of Spinal Meningoceles and Arachnoid Cysts

\title{
Ryan M. Dahlgren, MD
}

University of Oklahoma College of Medicine, Oklahoma City, OK, Eli M. Baron, MD

Temple University Department of Neurosurgery, Philadelphia, PA

Alexander R. Vaccaro, MD

Thomas Jefferson University Department of Orthopaedics, Philadelphia, PA

Please send all correspondence to:

\author{
Alexander R. Vaccaro \\ Rothman Institute \\ 925 Chestnut Street \\ Philadelphia, PA 19107 \\ 800-321-9999
}

fax: $215-503-0580$

Alexvaccaro3@aol.com 
Background

Spinal cysts refer to cavities that occur within the spinal cord substrate itself or its coverings and can occur throughout the length of the spinal column. This review will focus on 2 seen anomalies, spinal meningoceles and spinal arachnoid cysts and will review current classification systems, pathophysiology, diagnostic evaluations and treatment options.

Before discussing spinal meningocele, a brief review of dysraphism is warranted as spinal meningocele is a form of closed neural tube defect. Spinal dysraphism is characterized by failure of differentiation and/or fusion of dorsal midline structures through the embryonic developmental stages of gastrulation, primary neurulation, and secondary neurulation . Dysraphism is divided into 2 clinical subsets: open and closed. In open dysraphism the neural placode is exposed to the environment giving rise to entities such as myelomeningocele, hemimyelocele, myeloschisis, which are almost always associated with Chiari type II malformations. Closed spinal dysraphism, by contrast, is characterized by neural arch defects covered with intact skin. Closed dysraphism can be further divided into 2 subsets based on the presences or absence of a subcutaneous mass. Liposchisis, lipomyelomeningocele, meningocele, or myelocystocele may present as closed dysraphism with a mass, whereas, closed spinal dysraphism without a mass comprise complex dysraphic states ranging from complete dorsal enteric fistula to neurenteric cysts, split cord malformation, dermal sinus, caudal regression, spinal segmental dysgenesis, bony spina bifida, tight filum terminale, filum or intradural lipomas, and persistent terminal ventricle ${ }^{1}$. 
Spinal meningocele is defined as a protrusion of the spinal meninges through a defect in the vertebral column or foramina usually is association with a congenitally dysraphic vertebrae, with the spinal cord remaining entirely confined to the vertebral canal ${ }^{2,3}$. These lesions are frequently identified in a posterior location over the thoracic and sacral areas at birth and constitute about $10 \%$ of all patients with spina bifida ${ }^{2}$. Much more rarely seen are meningoceles protruding through anterior, lateral or anterolateral defects. One example of such is the exceedingly rare anterior sacral meningocele. More than three-quarters of cases are found in females. This may reflect, however, the fact that women of reproductive age are more likely to undergo pelvic examination than males. Interestingly, uterine anomalies are frequently found in association with anterior meningoceles ${ }^{4}$. An anterior sacral mass with an associated sacral defect when present with an anorectal anomaly is known as Currarino's triad ${ }^{5}$. Another rare form of meningocele is the non-dysraphic meningocele, characterized by the absence of a congenital defect of the vertebrae. These are usually located in the anterior thoracic level and are frequently associated with neurofibromatosis, or less commonly with Marfan's syndrome ${ }^{2}$.

Spinal arachnoid cysts are uncommon arachnoid protrusions that result in a collection of cerebrospinal fluid that can occur in a perineural, extradural, intradural, or intra-extradural site ${ }^{6-}$ ${ }^{8}$. Extradural cysts exist as outpouchings of the arachnoid that communicate with the intraspinal subarachnoid space through a small defect in the dura ${ }^{9,10}$. Intradural spinal arachnoid cysts usually consist of multiple lobules ${ }^{11}$. For our purposes the discussion here will be restricted to intradural arachnoid cysts. Arachnoid cysts are expanding lesions covered by a lining of arachnoid-like cells ${ }^{6,12}$. Histologically, cells lining arachnoid cysts do not immunostain with antibodies against GFAP, S-100, transthyretin (prealbumin), and CEA, helping to differentiate arachnoid cysts from epithelial cysts ${ }^{13}$. 
These lesions are located posterior to the spinal cord in $80 \%$ of cases, but have also been identified anteriorly and, rarely, laterally within in the dentate ligaments. Most frequently they occur in the thoracic spine $(70 \%)$ or at the thoracolumbar junction $(12 \%)$, but they can also be found in the lumbosacral (13\%) and cervical (3\%) spine ${ }^{12}$. Men and women seem to be equally affected, usually in the third through fifth decades of life ${ }^{14}$.

Difficulties have arisen in the classification of spinal arachnoid cysts because the cause and pathogenesis of these lesions are still debated. The nomenclature for this entity is also confusing as intradural arachnoid cysts are variously referred to as subdural arachnoid cysts, subarachnoid cysts, leptomeningeal cysts, arachnoid diverticula, and meningeal hydrops ${ }^{15,16}$. Arachnoid cysts may be classified as primary or secondary. Primary cysts most likely arise during development and may expand throughout life and progressively displace spinal tissue. Secondary cysts follow a variety of spinal insults including head injury, hemorrhage, chemical irritation, meningitis, and tumors ${ }^{17,18}$. In 1988 , Nabors et al. classified spinal cysts simply into three major categories on the basis of surgical, radiological, and histological criteria. Type I are spinal extradural meningeal cysts without spinal nerve root fibers (two subclassifications are defined as Type IA-extradural meningeal cyst and Type IB-sacral meningocele). Type II are spinal extradural meningeal cysts with spinal nerve root fibers (Tarlov cyst), and Type III are spinal intradural cysts, which are intradural spinal arachnoid cysts ${ }^{19}$. Intradural spinal arachnoid cysts should be differentiated from Tarlov cysts, which are extradural meningeal dilatations of the posterior spinal nerve root sheath. They have potential but not actual communication with the spinal subarachnoid space and usually occur distal to the junction of the posterior nerve root and dorsal root ganglion ${ }^{20}$. Tarlov cysts are discussed in another article in this publication. 


\section{Pathophysiology}

Spinal meningoceles are usually a form of dysraphism and are thought to arise during development. Development of the spinal cord is traditionally divided into 3 periods: gastrulation, primary neurulation and secondary neurulation. During gastrulation (weeks 2-3), the embryo undergoes conversion from a bilaminar to a trilaminar structure with establishment of the nuchal cord. This is followed during gestational weeks 3 and 4 by primary neurulation where the upper $9 / 10^{\text {th }}$ of the spinal cord is formed. Finally secondary neurulation and retrogressive differentiation occur in weeks 5 to 6 with formation of the conus medullaris and filum terminale ${ }^{1}$. Lumbar meningoceles are believed to occur as a disorder of secondary neurulation. While patients with meningoceles are usually neurologically normal, $90 \%$ of patients with meningocele have associated occult spinal lesions such as tight filum terminale, split cord malformation, and epidermoids. Subsequent tethering of the spinal cord may lead to progressive neurological deficit ${ }^{21}$.

Anterior sacral meningoceles result from failure of fusion of the sacrum with subsequent herniation of the sacrum meniges into the sacral hollow. Because of their occult location they typically present later on in life with protean neurologic, urological or gastrointestinal complaints ${ }^{4}$. Anterolateral meningoceles are very rare lesions that have been reported in association with neurofibromatosis and Marfan's syndrome. They are postulated to occur because of congential mesodermal dysplasia and hypoplastic bone changes ${ }^{2,22}$.

Arachnoid cysts likely result from alterations in the meningeal layer of the spine and the arachnoid trabeculae that overlie the spinal cord. Whether this is the result of a congenital malformation or from a causative factor such as previous trauma, inflammation, surgery, subarachnoid hemorrhage, or are completely idiopathic is a greatly debated issue ${ }^{13,14,21,23-26}$. The 
rare association of these lesions with neural tube defects may support the idea of a congenital etiology ${ }^{27}$. Perret et al. theorized that these lesions develop from the septum posticum of Schwalbe, an arachnoid membrane dividing the midline posterior cervical and thoracic subarachnoid space ${ }^{28}$. But problems with this theory have arisen as primary arachnoid cysts have been identified anterior to the spinal cord. Fortuna et al has suggested that incarceration of arachnoid granulations may produce cerebral spinal fluid that becomes entrapped in arachnoid diverticula. These sequestered pockets of fluid lead to further disruption of normal pulsatile CSF flow and thus are capable of expanding and developing into cysts ${ }^{16,29}$. The finding of melanocytes in an arachnoid cyst by Morioka et al. led to the idea that emigrating melanocytes from the neural crest migrated selectively to the original tissue of the arachnoid membrane, which developed an anomalous proliferation in the arachnoid diverticula or septum posticum, resulting in an arachnoid cyst ${ }^{23}$. This theory is based on congenital melanocytic nevi having nevus cells in the dermis congenitally, which emigrate from the neural crest to the dermis at 10 weeks of gestation in primates . Spiegelmann et al. reported that the histological examination of an intradural arachnoid cyst revealed hemosiderin containing macrophages trapped in the cyst wall, along with the findings of scarred arachnoid and adhesions at surgery, which led them to consider the arachnoid cyst to be a delayed consequence of the previous injury sustained by the patient ${ }^{30}$. A hydrodynamic theory in which normal CSF pulsations dilate weak areas of arachnoid and progressively enlarge into a cyst by the everyday variations in the cerebrospinal fluid hydrodynamics suggests that the mechanism of cyst enlargement and the degree of communication with the subarachnoid space is possibly related to a ball valve effect at the neck of the diverticulum ${ }^{10,12,18}$. Both spinal meningoceles and arachnoid cysts have also been 
described in patients with Marfan syndrome, neurofibromatosis, autosomal dominant polycystic kidney disease, and generalized connective tissue disorders of uncertain type ${ }^{31,32}$. 


\section{Patient Presentation}

Patients with spinal arachnoid cysts are most often asymptomatic with discovery of these lesions usually being made incidentally on spinal imaging for other reasons. When patients are symptomatic they usually present with pain, followed by progressive spastic or flaccid paraparesis. Other symptoms include sensory changes, sexual or urinary dysfunction, and local or diffuse radicular pain ${ }^{16,27,33}$. Intermittent exacerbation of symptoms may occur and is thought to be related to the fluctuation of neural compression by the cyst ${ }^{14,18}$. This fluctuation is theorized to occur when cerebrospinal fluid pressure is temporarily raised and fluid enters the cyst on straining and coughing ${ }^{14}$. However, kinematic MRI studies of extradural arachnoid cysts have demonstrated that cyst size may actually be reduced during Valsalva maneuver, where cord compression occurs during straining secondary to pressure contributed by the extradural venous plexus and the cyst combined. With cessation of Valsalva maneuver, the cyst resumes its normal caliber and the cord is no longer compressed ${ }^{10}$. Regardless, initial complaints are usually protracted and can mimic the waxing and waning disease process of multiple sclerosis.

Symptomatic patients may have a progressive course related to compression of the spinal cord or nerve roots.

Cyst location also plays an important role in patient presentation. Anterior cysts have been found to more likely cause weakness and myelopathy, whereas dorsal cysts presented more commonly with neuropathic pain and numbness. It is postulated that local compression of spinal tracts by the cyst may explain the difference in symptoms, or alternatively, ventral lesions may produce vascular compression in the distribution of the anterior spinal artery and thus cause weakness or myelopathy ${ }^{16}$. Rare cases of bizarre symptoms resembling angina have also been 
reported in the literature. These symptoms have been postulated to arise through aberrant stimulation of sympathetic chain ganglions through upper thoracic spinal nerve compression in conjunction with venous engorgement caused by physical exertion at the pathologic segment ${ }^{24}$. Additionally, syringomyelia has been associated with spinal arachnoid cysts, which may cause further neurologic signs and symptoms ${ }^{34}$.

Meningoceles are most often diagnosed during infancy during the third trimester, via maternal screening ultrasound. Ultrasound can examine the contents of the cyst and also visualize other associated spinal anomalies. Additionally, meningocele may present as a dorsal mass at birth. Other masses to consider in the infant at birth include sacrococcygeal teratoma, myelocystocele, lipomyelomeningocele, lipoma, and liposchises.

In adults, meningoceles are much rarer. Presentations described include that of progressive paraparesis or pain ${ }^{35}$. Anterior sacral meningoceles have been described causing abdominal pain and radicular symptoms along with meningeal signs ${ }^{5}$. Additionally Kontopolous et al described a case where a woman presented with constipation, difficulty with sexual intercourse and an abdominal mass on examination ${ }^{4}$.

\section{Diagnostic Studies}

When spinal meningoceles or symptomatic arachnoid cysts are suspected, early diagnosis is essential, especially because patients with a short history of symptoms are more likely to benefit from surgery. The differential diagnosis includes cystic neoplastic lesions, parasitic foci, meningocele, and arachnoid cysts ${ }^{16}$. Plain radiographs are helpful in showing enlargement of the spinal canal, posterior vertebral body scalloping, pedicle erosion, widening of the interpedicular distance, or thinning of the laminae usually produced by spinal meningoceles or 
spinal arachnoid cysts ${ }^{16}$. Myelography and postcontrast CT myelography are diagnostic tools that have been used, but MRI, if available, is the diagnostic procedure of choice for preoperative surgical planning and postoperative follow-up in patients with these types of cystic mass lesions ${ }^{14,15}$. MRI has the advantage of being noninvasive and having superior anatomical visualization. The primary MRI finding is an intradural, extramedullary space-occupying lesion with T1- and T2-weighted signal intensities identical to that of cerebrospinal fluid. A heterogeneous signal intensity on T2-weighted MRI, depending on the flow effect in the cyst fluid, may be the only evidence to indicate the presence of an abnormal fluid collection ${ }^{11,36}$. If the lesion extends into the epidural space, the difference in intensity between the arachnoid cyst or meningocele and the epidural fat is clearly shown on $\mathrm{MRI}^{27}$. MRI also allows for varying degrees of cord atrophy and the extent of myelomalacia to be assessed, which can be helpful in predicting neurologic outcomes ${ }^{21}$.

Cardiac-gated cine MRI (CMRI) is an additional method to noninvasively visualize arachnoid cysts. CMRI has the advantage of providing flow information by direct observation of tissue motion, obtaining 16 to 20 images per cardiac cycle ${ }^{36}$. CMRI is able to indicate abnormal cystic fluid motion and its influence on the spinal cord, such as dynamic cord compression and decompression ${ }^{11}$. This also allows identification of the cystic wall and possibly septum to be opened surgically ${ }^{10}$.

For meningoceles, workup of the infant should include a spinal MRI scan, as numerous associated abnormalities have been reported. In the adult presenting with pain and or progressive paraparesis, MRI, in addition to plain radiographs of the spine, should be obtained. Anterior sacral meningocele workup includes pelvic examination, lumbosacral MRI, and abdominal ultrasound. 
Treatment and Surgical approaches

Many arachnoid cysts are asymptomatic and are discovered incidentally \{Williams, 2002 \#21\}. These patients should undergo MRI with and without contrast to ensure the presence of a simple arachnoid cyst which does not need to undergo any intervention. If a spinal arachnoid cyst becomes symptomatic (causing myelopathy or significant radiculopathy), early surgical treatment of these cysts provides the best chance for resolution of symptoms and functional recovery $^{15}$.

Intradural spinal arachnoid cysts can usually be addressed via a posterior approach. Typically, a multilevel laminectomy is performed with intraoperative ultrasonography being used to confirm cyst size, location and morphology, prior to durotomy. The dura is then opened and the cyst is fenestrated into the subarachnoid space followed by cyst wall resection. While aggressive cyst removal may be the best way to prevent cyst recurrence ${ }^{15,37,38}$, a more limited approach may be safer. An arachnoid cyst adherent to the dura may be aggressively removed if possible while an epipial cyst wall may be left undisturbed in order to minimize the risk of spinal cord injury. Ventrally located cysts can be treated similarly, but without aggressive arachnoid removal secondary to potential cord injury. Wang et al advocates ultrasonography at this point to confirm that ventral cysts are significantly reduced in size. If not they recommend placement of a small silastic shunt to drain cerebrospinal fluid into the subarachnoid space. In the presence of a concurrent syrinx, if the syrinx is noted to decompress several minutes post decompression of the arachnoid cyst, then a shunt is not performed; if the syrinx does not decompress, a silastic shunt is placed from the syrinx into the subarachnoid space. Closure of the 
dura is done primarily, except where a dural closure is felt to restrict the subarachnoid space and then a duraplasty is performed ${ }^{16}$.

Other procedures have also been utilized to treat intradural spinal arachnoid cysts, although they are in general considered to be second line procedures. Bellavia et al described MRI guided percutaneous aspiration of a thoracic arachnoid cyst with good results at 1 year ${ }^{18}$. Shunting the spinal arachnoid cyst into the peritoneal or pleural spaces has also been extensively described ${ }^{14}$.

When a meningocele is discovered at infancy, repair should ensue early on to prevent sac injury, cerebrospinal fluid leak, and infection. Surgical repair consists of exposing the neck of the meningocele (ideally at its junction with normal dura) via laminectomy or laminotomy, excision or plication of the sac, and repair of the defect with paraspinal fascia. The neck is defined circumferentially at the level of the paraspinal muscles, the sac opened, and the contents are inspected to ensure they are devoid of neural tissue. If this is found to be the case then the sac is amputated. The surgeon should be aware of fibrous bands or entrapped nerve roots in the meningocele sac, especially where the sac is narrow ${ }^{21}$. Nevertheless, considering its association with other spinal lesions often responsible for the tethered cord syndrome, patients should have neurologic, orthopaedic and urologic follow-up to monitor for the development of signs and symptoms suggestive of cord tethering.

In the unusual case of adult meningocele, surgical therapy should be considered if neurologic symptoms such as paraparesis or bladder dysfunction are present or if the meningocele is causing pain. Surgery consists of laminectomy, closure of communication between the thecal sac and meningocele and arachnoid dissection if adhesions are present. 
Intradural pathology such as dermoids, lipoma or fatty filum causing a tethered cord should also be addressed if present. Good results have been reported ${ }^{35}$.

Anterior sacral meningoceles can be treated via a variety of approaches. Sacral laminectomy is a commonly used approach. Approaching the ostium via sacral laminectomy with subsequent durotomy, allows for ligation of the ostium of an anterior sacral meningocele (via suturing) to disrupt its connection with the thecal sac. This may be difficult to do where the ostium is very large or neural elements run near the ostium. Transdural sutures with imbrication of the dura to preserve nerve roots may prove to be a useful technique. Additionally, associated intradural anomalies (such as fatty filum leading to tethered cord) can be treated.

Other approaches for treating anterior sacral meningoceles have also been described. If the ostium of the anterior sacral meningocele communicating with the thecal sac is less than 10 $\mathrm{mm}$, a laparoscopic approach may be taken to ligate the ostium. This may be done via an anterior or posterior approach, where a suture is placed around the ostium. An open anterior abdominal approach may be used if the neck of the meningocele is too large to be ligated from a posterior approach. Though it can also address cases with a solid anterior mass component, the anterior approach does not effectively address cases with caudal spinal cord anomalies. A posterior midsagittal approach has also been described which allows correction of associated anorectal anomalies and resection of any solid masses associated with the meningocele. Since this approach is done very inferiorly, it may be difficult to access the neck of a meningocele originating from the proximal sacrum ${ }^{39}$. Alternatively, lumboperitoneal shunting has been used with good result ${ }^{40}$.

Conclusions 
Spinal arachnoid cysts and meningoceles are cystic lesions of the spinal cord coverings which all orthopaedic spine surgeons and neurosurgeons should be aware of. The adult spine surgeon is much more likely to encounter a symptomatic or asymptomatic spinal arachnoid cyst than a symptomatic or asymptomatic meningocele which is a rare entity often encountered by a medical care provider in the pediatric years. Meningoceles are treated surgically along with a medical screenning for associated lesions. Spinal arachnoid cysts that are asymptomatic are usually incidental findings and need no further intervention. Symptomatic spinal arachnoid cysts should be addressed surgically before neurologic deficits are irreversible. 
Figure Legends

Figure $1 \mathrm{a} \& 1 \mathrm{~b}$

T2 weighted sagittal MRI demonstrates a ventral arachnoid cyst extending from C6 to T5. Axial image showing the cyst (arrow with resultant) dorsal displacement of the cord.

Figure $2 \mathrm{a} \& \mathrm{~b}$

T2 weighted sagittal and axial MRI demonstrating a large dorsal thoracic intradural spinal arachnoid cyst with associated cord compression and resultant myelopathy. This patient had undergone laminectomy and cyst fenestration without removal of arachnoid adherent to the dura: while this resulted in temporary relief of the patient's symptoms, the cyst recurred several months afterwards. 
References

1. Feltes $\mathrm{CH}$, Fountas KN, Dimopoulos VG, et al. Cervical meningocele in association with spinal abnormalities. Childs Nerv Syst 20:357-361, 2004

2. Gocer AI, Tuna M, Gezercan Y, et al. Multiple anterolateral cervical meningoceles associated with neurofibromatosis. Neurosurg Rev 22:124-126, 1999

3. Salomao JF. Cervical meningocele in association with spinal abnormalities. Childs Nerv Syst 21:4-5; author reply 6, 2005

4. Kontopoulos EV, Oyelese Y, Nath C, et al. Maternal anterior sacral meningocele in pregnancy. J Matern Fetal Neonatal Med 17:423-425, 2005

5. Jeon BC, Kim DH, Kwon KY. Anterior endoscopic treatment of a huge anterior sacral meningocele: technical case report. Neurosurgery 52:1231-1233; discussion 1233-1234, 2003

6. Karnezis IA, Crawshaw CC. Unknown case. Spinal claudication caused by an arachnoid cyst. Spine 26:2757-2758, 2001

7. Pego-Reigosa R, Branas-Fernandez F, Martinez-Vazquez F, et al. Craniospinal intradural arachnoid cyst. Archives of Neurology 57:128, 2000

8. Quinones-Hinojosa A, Sanai N, Fischbein NJ, et al. Extensive intradural arachnoid cyst of the lumbar spinal canal: case report. Surg Neurol 60:57-59, 2003

9. Safriel YI, Sanchez G, Jhaveri HS. Giant anterior cervicothoracic arachnoid cyst. Spine 27:E366-368, 2002 
10. Doita M, Nishida K, Miura J, et al. Kinematic magnetic resonance imaging of a thoracic spinal extradural arachnoid cyst: an alternative suggestion for exacerbation of symptoms during straining. Spine 28:E229-233, 2003

11. Shimizu H, Tominaga T, Takahashi A, et al. Cine magnetic resonance imaging of spinal intradural arachnoid cysts. Neurosurgery 41:95-100, 1997

12. Fobe JL, Nishikuni K, Gianni MA. Evolving magnetic resonance spinal cord trauma in child: from hemorrhage to intradural arachnoid cyst. Spinal Cord 36:864-866, 1998

13. Hirano A, Hirano M. Benign cysts in the central nervous system: neuropathological observations of the cyst walls. Neuropathology 24:1-7, 2004

14. Lee HJ, Cho DY. Symptomatic spinal intradural arachnoid cysts in the pediatric age group: description of three new cases and review of the literature. Pediatr Neurosurg $35: 181-187,2001$

15. Bassiouni H, Hunold A, Asgari S, et al. Spinal intradural juxtamedullary cysts in the adult: surgical management and outcome. Neurosurgery 55:1352-1359; discussion 13591360,2004

16. Wang MY, Levi AD, Green BA. Intradural spinal arachnoid cysts in adults. Surg Neurol 60:49-55; discussion 55-46, 2003

17. Price SJ, David KM, O'Donovan DG, et al. Arachnoid cyst of the craniocervical junction: case report. Neurosurgery 49:212-215, 2001

18. Bellavia R, King JT, Jr., Naheedy MH, et al. Percutaneous aspiration of an intradural/extradural thoracic arachnoid cyst: use of MR imaging guidance. Journal of Vascular \& Interventional Radiology 11:369-372, 2000 
19. Nabors MW, Pait TG, Byrd EB, et al. Updated assessment and current classification of spinal meningeal cysts. J Neurosurg 68:366-377, 1988

20. Acosta FL, Jr., Quinones-Hinojosa A, Schmidt MH, et al. Diagnosis and management of sacral Tarlov cysts. Case report and review of the literature. Neurosurg Focus 15:E15, 2003

21. Ersahin Y, Barcin E, Mutluer S. Is meningocele really an isolated lesion? Childs Nerv Syst 17:487-490, 2001

22. Rainov NG, Heidecke V, Burkert W. Thoracic and lumbar meningocele in neurofibromatosis type 1 . Report of two cases and review of the literature. Neurosurg Rev 18:127-134, 1995

23. Morioka M, Hamada J, Ohmori Y, et al. Spinal arachnoid cyst containing nevus cells in a patient with a large congenital melanocytic nevus: case report. Neurosurgery 55:983-984, 2004

24. Kumar K, Malik S, Schulte PA. Symptomatic spinal arachnoid cysts: report of two cases with review of the literature. Spine 28:E25-29, 2003

25. Jean WC, Keene CD, Haines SJ. Cervical arachnoid cysts after craniocervical decompression for Chiari II malformations: report of three cases. Neurosurgery 43:941944; discussion 944-945, 1998

26. Jea A, Navarro R, Green BA. Rapid expansion of a ventral arachnoid cyst after syringosubarachnoid shunting in the thoracic spinal cord: case report. Surgical Neurology 64:8689; discussion 89, 2005

27. Abou-Fakhr FS, Kanaan SV, Youness FM, et al. Thoracic spinal intradural arachnoid cyst: report of two cases and review of literature. Eur Radiol 12:877-882, 2002 
28. Perret G, Green D, Keller J. Diagnosis and treatment of intradural arachnoid cysts of the thoracic spine. Radiology 79:425-429, 1962

29. Fortuna A, La Torre E, Ciappetta P. Arachnoid diverticula: a unitary approach to spinal cysts communicating with the subarachnoid space. Acta Neurochir (Wien) 39:259-268, 1977

30. Spiegelmann R, Rappaport ZH, Sahar A. Spinal arachnoid cyst with unusual presentation. Case report. J Neurosurg 60:613-616, 1984

31. Alehan FK, Gurakan B, Agildere M. Familial arachnoid cysts in association with autosomal dominant polycystic kidney disease. Pediatrics 110:e13, 2002

32. Schievink WI, Torres VE. Spinal meningeal diverticula in autosomal dominant polycystic kidney disease. Lancet 349:1223-1224, 1997

33. Muthukumar N. Anterior cervical arachnoid cyst presenting with traumatic quadriplegia. Childs Nerv Syst 20:757-760, 2004

34. Clifton AG, Ginsberg L, Webb WJ, et al. Idiopathic spinal arachnoid cyst and syringomyelia. Br J Radiol 60:1023-1025, 1987

35. Klekamp J, Raimondi AJ, Samii M. Occult dysraphism in adulthood: clinical course and management. Childs Nerv Syst 10:312-320, 1994

36. Neo M, Koyama T, Sakamoto T, et al. Detection of a dural defect by cinematic magnetic resonance imaging and its selective closure as a treatment for a spinal extradural arachnoid cyst. Spine 29:E426-430, 2004

37. Osenbach RK, Godersky JC, Traynelis VC, et al. Intradural extramedullary cysts of the spinal canal: clinical presentation, radiographic diagnosis, and surgical management. Neurosurgery 30:35-42, 1992 
38. Alvisi C, Cerisoli M, Giulioni M, et al. Long-term results of surgically treated congenital intradural spinal arachnoid cysts. J Neurosurg 67:333-335, 1987

39. Tani S, Okuda Y, Abe T. Surgical strategy for anterior sacral meningocele. Neurol Med Chir (Tokyo) 43:204-209, 2003

40. Rukskul P. Lumbo-peritoneal shunting improved spinal cord compression due to a large anterior sacral meningocele. J Med Assoc Thai 88:265-268, 2005 